Carlos Dnummond
de Andrade 


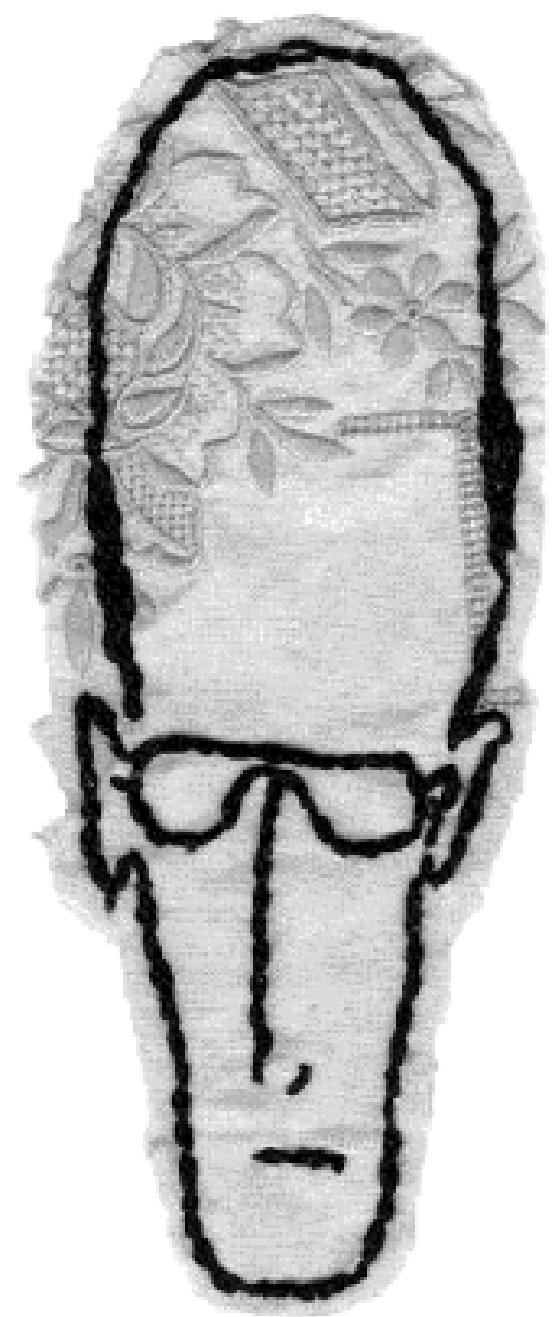

Cópia de autocaricatura de Drummond bordada sobre pano de madame, por Cássia Macieira - 2002. 


\title{
E agora, Carlos? Amparo e desamparo na poética de Drummond
}

\author{
Rebecca Monteiro I UFMG
}

\author{
Chegou um tempo em que não adianta morrer. \\ Chegou um tempo em que a vida é uma ordem. \\ A vida apenas, sem mistificação. \\ Drummond - Os Ombros Suportam o Mundo \\ Este é tempo de divisas, \\ tempo de gente cortada. \\ (..) \\ E continuamos. É tempo de muletas. \\ Drummond - Nosso Tempo
}

Resumo: Estudo sobre a questão do amparo em Carlos Drummond de Andrade. Uma politica recorrente de amparo à falibilidade bumana e de redução de sua complexidade inerente (patrocinada por uma metafísica da posicionalidade) é questionada e deslocada pelo poeta. Através de uma estratégia poética calcada na ambigüidade, na inquietude e no deslocamento de valores, Drummond redimensiona os objetivos da atividade literária, tornando-a mais política e menos compensatória. Palavras-chave: ambigüidade, valores, politico.

Se ainda continuamos Carlos, apesar e por causa mesmo de sua poesia, é também porque as muletas permanecem, doces e ásperas ainda, 
como em sua época. Uma época que também é a nossa. ${ }^{1}$ Dessa época e dessas muletas salta uma gente cortada e estranha que exigiu e vem exigindo - e você, Carlos, ouviu esse apelo - um corpo menos completo e menos amparado. Nesse salto e nessa exigência é denunciada, sobretudo, uma forma de compreender o corpo humano e suas muletas (reais ou imaginárias) que, se não é de todo errônea, ainda é muito ingênua. E se você, poeta, compreendeu como poucos essa ingenuidade, também recorreu a ela, tão incontáveis vezes quanto delas fugiu, estupidificado. Mas fuga e retorno são dois lados de uma mesma escrita do desejo. Um desejo inconstante, mas miúdo, por muletas. Seja porque sejam doces. Seja porque sejam ásperas.

Digo que as muletas são doces porque doce é a consistência de tudo aquilo que suaviza, que ampara, que embala. Em princípio, apenas os homens incompletos, infelizes ou mendicantes deveriam ser amparados. E as muletas do amparo são sempre doces. Mas se afirmei que a forma de compreender o corpo humano é ingênua, é justamente porque está implícito na hipótese da muleta que ampara que pudesse haver homens completos, totalmente felizes ou saciados. As muletas não servem apenas aos homens partidos porque sabemos que todo andar humano já é, por si só, claudicante, imperfeito e inseguro. Todos trazemos muletas ou ferramentas semelhantes porque a muleta é a própria manifestação da falta, não a sua superação. Ela suplementa a falta de uma perna com duas. Ela suplementa a falta de uma tristeza com outra. Mas a muleta é um artifício para superar o insuperável. Por isso ela é áspera, porque desampara a incompleta condição humana. Ela ressalta o perigo. Ela avisa que todo amparo é impossível. Estamos prestes a cair. E "caímos, imorredouramente".

Mas não sejamos ingênuos. Não existem muletas apenas doces ou apenas ásperas. A doçura e a aspereza das muletas se confundem. A muleta já é agora doce não porque ampara, mas porque não ampara nada. Ou porque ampara de forma impura, ou porque ampara demais. Seja porque mostra a falibilidade da perna humana, seja porque a recusa, a muleta é, ao mesmo tempo, um alívio e uma blasfêmia. Assim também é o texto, Carlos, e você o sabia. Quando o andar humano depara com uma pedra no meio do caminho, ${ }^{3}$

1. ANDRADE, 1988. p. 70: "Nosso Tempo".

2. ANDRADE, 1996. p. 91: "Queda".

3. ANDRADE, 1988. p. 45: "No Meio do Caminho". 
ele tropeça na impureza dos caminhos e dos destinos. A pedra do caminho recusa o amparo e a tranqüilidade do caminho puro, mas também permite a possibilidade de fuga. O caminho é imperfeito, vamos voltar? Não, continuemos, Carlos. E essa continuidade está atravessada pelas seqüelas da sua poesia. Sua poesia nos deixa desamparados, mas justamente aí é que prosseguimos.

Um homem de muletas não é um homem incompleto. É um homem sustentado no ar. Mas esse amparo, que é falso, é um arremedo de segurança. E esse arremedo é também uma forma mímica do andar. Nesse falso amparo, no entanto, não vejo apenas uma negatividade, porque as formas do falso podem ser instigantes. Nesse ponto me alongarei um pouco mais, porque é preciso desmistificar aquele corpo "inteiro e único" com que você, Carlos, finaliza a "Missão do Corpo". ${ }^{4}$ Principalmente porque um ser inteiro e único implicaria a existência de um andar solene, perfeito, incomparável. Tal andar seria o oposto mais distante do andar inseguro do homem de muletas. $O$ homem de muletas seria, nessa busca ontológica pelo corpo pleno, a forma mais horrível de aberração. O homem sem pernas devolve ao homem completo sua impossível perfeição. O homem sem pernas é horrendo, não porque seja incompleto ou imperfeito, mas porque sua mímica do andar nos devolve a impossibilidade da perfeição. Vejamos como isso acontece.

A forma de diferença que é a mímica é descrita por Homi Bhabha principalmente como um olhar que é parcial e duplo simultaneamente. Na mímica, o jogo de olhares entre o que imita e o que é imitado encena o desejo "de um Outro reformado, reconhecível, como sujeito de uma diferença que é quase a mesma, mas não exatamente". Um desejo que forma sua visibilidade no lugar da interdi(c)ção. Assim, o andar de muletas é quase um andar perfeito, mas não exatamente. Reformando o homem sem pernas, estamos "na encruzilhada entre o que é conhecido e permitido [o homem completo] e o que, embora conhecido, deve ser mantido oculto [a falta original do homem]". ${ }^{6}$

4. ANDRADE, 1996. p. 71. "Será mesmo acaso,/ será lei divina ou dragonária/ que me parte e reparte em pedacinhos?/ Meu corpo, minha dor,/ meu prazer e transcendência,/ és afinal meu ser inteiro e único."

5. BHABHA, 1998. p. 130. Bhabha adapta nessa afirmativa uma formulação de Samuel Weber sobre a visão marginalizante da castração. Cf. WEBER. S. The sideshow, or: remarks on a canny moment. Modern Language Notes, v. 88, n. 6, p. 112, 1973. Grifos nossos.

6. ВНАВНА, 1998. p. 135. 
Ora, se só nos é permitido conhecer o homem inteiro, é um alívio encontrar em sua poesia, Carlos, o chamado dos homens claudicantes, das velhas paralíticas, dos surdos-mudos. ${ }^{7}$ O José sem dinheiro, sem mulher, sem cigarro, sem discurso, sem dia, sem bonde, sem incoerência é quase o homem perfeito se não lhe faltasse tanto. ${ }^{8}$ Aquilo que falta em José acaba questionando a superioridade dos corpos inteiros, perfeitos e soberanos sobre os corpos da falta. Esse questionamento corrompe a perspectiva metafísico-logocêntrica ocidental em sua insistente procura pela essência. ${ }^{9}$ E acaba por enfatizar que aqueles corpos "inteiros e únicos" - enquanto identidades plenamente reconhecíveis - são uma invenção.

Sua poesia, Carlos, também quer denunciar essa invenção de uma essência pura para o homem, muito embora alguns poemas recaiam, às vezes, no campo metafísico. Apesar disso, é o terreno do estereótipo que será denunciado em sua luta, Carlos. Como o mito do homem completo faz girar o sujeito em torno dos pivôs estereotípicos, o homem incompleto afasta-se de si próprio, de sua pele, de seu corpo, em sua total identificação com a positividade da "inteireza". No ato da recusa e da fixação, "o sujeito (...) é remetido de volta ao narcisismo do imaginário e sua identificação com um ego ideal que é inteiro". Enquanto isso, Carlos, você briga com a incompletude, com o conflito constante Eu-Outro, sabendo que a identidade do estereótipo está sempre ameaçada pela falta (uma vez que se reconhece a diferença, mas ela é recusada, ou mascarada). Assim, por exemplo, no belíssimo "A chave", vemos o interior, a

7. ANDRADE, 1988. p. 70-77: "Nosso Tempo".

8. ANDRADE, 1988. p. 61-63: "José".

9. Para Derrida (a partir de Heidegger), toda uma tradição filosófica ocidental funda-se sobre dois conceitos de verdade, complementares entre si e determinados pelo valor de presença. É verdadeiro o desvelamento da Presença, ou seja, é verdadeiro aquilo que apresenta o ente tal como ele é (adequatio/homoiosis), e é verdadeiro o desvelamento da totalidade do ente naquilo que ele é (alétheia). A partir desses conceitos de verdade temos uma metafísica determinada pelo valor de presença. Isso assegura que a história da cultura ocidental seja uma história da Verdade enquanto desvelamento de uma Essência original oculta em algum lugar, ou seja, temos uma história cujo caráter principal é o de revelação. Segundo Derrida, o questionamento da existência do centro, da fonte original, "amplia indefinidamente o campo e o jogo da significação", uma vez que "tudo torna-se discurso". Cf. DERRIDA, 1971. p. $231-232$.

10. BHABHA, 1998. p. 118. Grifos meus. 
essência, apenas vazios: "A chave de uma porta que não abre/ para o interior desabitado/ no solo que inexiste,/ mas a chave existe." Assim também em versos simples como "Todo ser humano é um estranho ímpar" e "Mas falta coragem e peço pra dentro./ Dentro não responde" ${ }^{13}$ e em estrofes tão intensas como em

Visito os fatos, não te encontro.

Onde te ocultas, precária síntese,

Penhor de meu sono, luz

Dormindo acesa na varanda?

Miúdas certezas de empréstimo, nenhum beijo

Sobe ao ombro para contar-me

A cidade dos homens completos. ${ }^{14}$

percebemos que uma contínua resistência ao amparo fácil da metafísica e do estereótipo se faz ouvir, pouco interessada no consolo:

permita cavalheir (o, a)

amig (o, a) me releve

este malestar

cantarino escarninho piedoso

este querer consolar sem muita convicção

o que é inconsolável de ofício

a morte é esconsolável consolatrix consoadíssima

a vida também

tudo também

mas o amor car (o, a) colega este não consola nunca de núncaras ${ }^{15}$

No entanto, apesar desse lavrar contínuo contra uma essência consoladora, em poemas como o já citado "Missão do Corpo", as imperfeições,

11. ANDRADE, 1988. p. 148-49.

12. ANDRADE, 1988. p. 145: "Igual-Desigual".

13. ANDRADE, 1988. p. 119: "Noturno".

14. ANDRADE, 1988. p. 70-77: "Nosso Tempo".

15. ANDRADE, 1988. p. 107: "Amar-Amaro".

16. ANDRADE, 1996. p. 71. 
incoerências e múltiplas repartições do corpo são lidas apenas como partes incompreensíveis de um todo mais perfeito. É como se o final do poema viesse cansado de uma avaliação mais imanente como em "O corpo se realiza vulnerável/ E solene" ${ }^{17}$ e em "Amo tuas imperfeições e maravilhas,/ Amo-as com gratidão, pena e raiva intercadentes" ${ }^{18}$ e, por fim, já exangue, recorresse à metafísica.

Fazem parte dos poemas metafísicos, por exemplo, "A Metafísica do Corpo" onde você, poeta Carlos, de novo inventa um além das unhas, um além da carne, onde a "música de esferas e de essências", 19 onde a "unidade inicial do mundo" chamam para uma outra vida. Finalmente, "eis que se revela o ser, na transparência/ do invólucro perfeito." ${ }^{21}$ Essa revelação do ser original, essa obsessão pelo perfeito, não são, nesse caso, ingênuas, dado o próprio título do poema. Sabem ser metafísicas, o que demonstra um olhar lúcido para a ambigüidade, mas talvez cansado das impurezas do caminho. No entanto, um poema nostálgico como "Fim de Casa Paterna" traz em si um passado "livre" e "infinito", de certa forma paralisado no tempo, de alguma maneira já morto. Esse isolamento do passado na perfeição e na unidade congelada não participa, no entanto, da sua profunda compreensão do passado-preente, seja como fantasma, seja como presença viva no corpo, dolorosamente viva, como no célebre "Confidência do Itabirano".

Mas cada uma das faltas em "José" redime as suas recaídas, Carlos, na metafísica, porque exercem uma subversão contínua às idéias de pureza, integridade e sentido. "José, para onde?" ${ }^{24}$ é o golpe final nas práticas discriminatórias e autoritárias, que exigem sempre um sentido, uma direção, uma utilidade. A sugestão perversa do poema, a retirada impassível de todas as

17. ANDRADE, 1996. p. 71.

18. ANDRADE, 1996. p. 71.

19. ANDRADE, 1988. p. 146.

20. ANDRADE, 1988. p. 146.

21. ANDRADE, 1988. p. 147.

22. ANDRADE, 1988. p. 121.

23. ANDRADE, 1988. p. 53-54. "E o hábito de sofrer, que tanto me diverte,/ é doce herança itabirana. (...) Itabira é apenas uma fotografia na parede./ Mas como dói!"

24. ANDRADE, 1988. p. 63. 
muletas, é exercida nos limites da identidade e da autoridade, entre a máscara e a imagem, entre tensões psíquicas e políticas. Tal estratégia não é apenas negativa ou apenas dialética, mas sim intensamente tradutória, ou como preferimos ainda colocar, intensamente traidora: "um modo de negação que busca não desvelar a completude do Homem, mas manipular sua representação". Assim, das margens do discurso ambivalente da identidade e da autoridade emerge esse modo de tradução/traição que é fundamentalmente desorientador e por isso mesmo desolador.

José não vai a lugar algum, embora marche. Todas as muletas que o tornavam um homem reconhecível foram retiradas. Mas o homem nu é um estranho. O limite do desamparo é, portanto, a própria impossibilidade de vida. Não existe o homem sem muletas. O próprio medo é também uma forma de amparo, como você nota, Carlos, em "O Medo":
Vem, harmonia do medo,
Vem, ó terror das estradas,
Susto na noite, receio
De águas poluídas. Muletas
Do homem só. ${ }^{26}$

Por muletas você poeta já terá entendido todo um universo de narrativas "do amparo", das religiões ao platonismo, da crítica literária à devoção pela hermenêutica e, finalmente, da poesia de embalar crianças ao futebol e ao circo. No entanto, a política do amparo humano funciona por meio de subterfúgios ainda mais sutis e incansáveis do que sonha a nossa vã dialética. Digo dialética e não filosofia, confiando na emenda machadiana à famosa frase de Hamlet.

E a vanidade da dialética precisou ser destacada por Machado para que pudéssemos lembrar que um dos meios mais eficazes que o homem encontrou de amparar a si mesmo foi a invenção de um corpo menos ambíguo para si mesmo. Essa invenção, amparada que foi nas determinações da dialética,

25. BHABHA, 1998. p. 101.

26. ANDRADE, 1988. p. 68-70.

27. "Em verdade, a conclusão não parecia estar nas premissas; era o caso de emendar outra vez Hamlet: 'Há entre o céu e a terra, Horácio, muitas cousas mais do que sonha a vossa vã dialética'. ASSIS, 1997. p. 224-225. 
corrigiu as estranhezas do corpo desejante do homem. Cortadas uma a uma, as ambivalências do corpo humano perderam as dissonâncias mutuamente intercambiáveis que percorrem o ambíguo. O corpo ficou feminino ou masculino. Branco ou negro. Forte ou fraco. Maior ou menor. Mas esse corpo, construído com a pureza, a completude e a parcialidade, estava apenas falsamente amparado.

Pelo que se viu até aqui, pode-se concluir que existem duas possibilidades nessa política do amparo em prol da integridade ideal do homem. A primeira delas trabalha na omissão da ambigüidade essencial que percorre a política do amparo e que reside na construção de um corpo inteiro com um corpo parcial. Assim, Carlos, nós vimos como - nas narrativas cotidianas, em boa parte da filosofia, nos textos da salvação, pela alma ou pelo corpo - o corpo pode ser tolhido em sua multiplicidade desconcertante para recair no ardil discursivo do ou/ou. Você denuncia isso de forma pungente em "Nosso Tempo", mas também em versos como:

Estou preso à vida e olho meus companheiros.

Estão taciturnos mas nutrem grandes esperanças.

Entre eles, considero a enorme realidade.

O presente tão grande, não nos afastemos.

Não nos afastemos muito, vamos de mãos dadas. ${ }^{28}$

Nessa profunda reflexão, Carlos, você percebe o falso amparo da esperança e se recusa a distribuir entorpecentes ou utopias serafinescas. ${ }^{29}$ Destaca a importância da política e o fortíssimo apelo do presente, que aliás é a matéria da política. No entanto, Carlos, não se mate ${ }^{30}$ ao encontrar homens carregados, arrastados para países imaginários, fáceis de habitar (ilhas perdem os homens), ${ }^{31}$ não se mate porque esse vício metafísico é ainda mais ardiloso do que a sua vontade desconstrutora, e retorna sempre sob novas formas. A política do amparo mais recorrente é essa primeira de que falei, ela inventa um corpo inteiro (que na verdade é apenas parcial) para o homem. Esse corpo corrige imperfeições e alça as faltas humanas no ar, sustentando-o no espaço como a mais engenhosa das muletas.

28. ANDRADE, 1988. p. 55: "Mãos Dadas".

29. ANDRADE, 1988. p. 56: "Mãos Dadas".

30. ANDRADE, 1988. p. 48: "Não se Mate".

31. ANDRADE, 1988. p. 56-57: "Mundo Grande". 
Por outro lado, é justamente porque a política do amparo é construída sobre essa ambigüidade enunciativa que uma terceira escolha é permitida. Escancarar a ambigüidade dos processos de amparo, desnudar as muletas ou multiplicá-las à exaustão são ardis discursivos que fogem das opções ou/ou que orientam nossa cultura: ou um, ou outro; ou branco, ou negro; ou mulher, ou homem. Se você toma, como eu afirmei antes, a muleta como um órgão de denúncia do falso amparo e não como um instrumento caritativo, ela passa a funcionar como suplemento, como menos que um e duplo, passando a funcionar como "modo de apropriação e de resistência". ${ }^{32}$ Passa do falso amparo às várias encenações do desamparo: o quase-desamparo; o desamparo exagerado, mas também falso; o desamparo-amparador, entre outras. Elas manipulam as corriqueiras encenações da política do amparo em suas mais variadas facetas: o amparo religioso, o amparo ideológico, o amparo erótico, o amparo civilizatório e tantos outros mais.

Assim, vejamos. O desamparo que salta, exagerado e hiperbólico das múltiplas faltas em "José", concentra uma traição-subversão que é profundamente restauradora em sua resistência à idéia de homem total. Nisso repousa a força do poema, porque só aí a idéia de uma vida sem transcendência e uma política sem o sonho da perfectibilidade poderiam ter lugar. ${ }^{33}$ Nesse ponto, Carlos, você escancara a série de muletas de tons variadíssimos que recuperam a-falta-a ser do homem. Mesmo que, em muitos momentos, sua poesia tenha sido uma poesia do amparo (ainda que o falso amparo também tenha sua força de perversão), em alguns poemas como "José", "Nosso Tempo", "Áporo", o desamparo violento é já uma violação ao corpo perfeito do homem. O homem esvaziado, seco, exangue até mesmo das muletas dos seus órgãos, mas mesmo assim resistente e resistindo. A imagem que me surge, ainda, é a da educação pela pedra, ensinada por João Cabral, que acontece principalmente como resistência "ao que flui e a fluir, a ser maleada". $\mathrm{E}$ ainda, a do soldado adormecido nas cercanias de Canudos, que Euclides da Cunha presenciou e descreveu tão delicadamente.

32. BНABHA, 1998. p. 174.

33. Cf. BНABHA, 1998. p. 100.

34. MELO NETO, 1994. p. 338: "A Educação pela Pedra".

35. CUNHA, 1981. p. 24. "E estava intacto. Murchara apenas. Mumificara conservando os traços fisionômicos, de modo a incutir a ilusão exata de um lutador cansado, retemperando-se em tranqüilo sono, à sombra daquela árvore benfazeja. Nem um verme - o mais vulgar dos trágicos analistas da matéria - lhe maculara os tecidos.Volvia ao turbilhão da vida sem decomposição repugnante, numa exaustão imperceptivel." Grifos meus. 
Já o trabalho com o quase-desamparo é uma construção híbrida que se dá pela violência de uma separação. Quando observamos, por exemplo, seu poema Nudez, ${ }^{36}$ de 1959, o acento metalingüístico registra a negação de uma escrita feita para os outros: "Não cantarei amores que não tenho..."; "Não cantarei o mar..."; "Não cantarei o morto....". Mais ainda, o silêncio proposital (que não é o silêncio, mas a marcação de sua presença) acusa a falibilidade da representação, a impossibilidade da comunicação e a tradução implícita em cada enunciação: ${ }^{38}$

Ou sabe? Algo de nós acaso se transmite,

Mas tão disperso, e vago, tão estranho,

Que, se regressa a mim que o apascentava,

O ouro suposto é nele cobre e estanho,

Estanho e cobre,

E o que não é maleável deixa de ser nobre,

Nem era amor aquilo que se amava.

Como Santiago, aliás, registrou em sua poética, onde está implícita também a dimensão política da linguagem: 40

A comunicabilidade com o outro pela palavra poética (...) é conquista e fracasso do individualismo e é, ao mesmo tempo, um ideal ascético de exigência introspectiva e de simplicidade humana, vale dizer, de responsabilidade cidadã e de aversão ao culto do escritor como alguém que, por exercer uma profissão dita nobre, difere dos outros. ${ }^{41}$

36. ANDRADE, 1988. p. 101-102.

37. ANDRADE, 1988. p. 101-102. Para todas as citações desse poema.

38. A respeito dessa questão, Derrida, sem dúvida, é a melhor fonte. Segundo ele, o significado é absolutamente relacional e também provisório. Assim, a "palavra escrita é 'diferença' na medida em que se oferece diferida (temporal e espacialmente) do que representa, reservada a uma decodificação contextual, inscrita numa cadeia de significantes. É a palavra que não se apresenta em sua 'pureza', oferecendo sua verdade pelo desvio de um significante que é estranho à sua própria realidade." SANTIAGO, 1976. p. 25. Grifos nossos. Cf. DERRIDA, 1971. Como um todo, mas principalmente p. 244-245.

39. ANDRADE, 1988. p. 101: "Nudez".

40. A maturidade política, segundo Bhabha, está na aceitação da existência das muitas formas de escrita política. Segundo ele, tanto a teoria quanto a atividade políticas são fundadas no discurso e a compreensão do discurso está intimamente ligada à compreensão da política. Cf. BHABHA, 1998. p. 46.

41. Cf. Posfácio de Silviano Santiago a Farewell: ANDRADE, 1996. p. 112. Grifos meus. 
Mas esse silêncio, essa separação do mundo alheio, é, ao mesmo tempo, um ir ao encontro de algo. Mesmo que esse algo tenha um leve tom metafísico, ainda assim o encontro com o eu não se configura em um tempo pleno, mas com uma "anulação do tempo em tempos vários". ${ }^{2}$ O quasedesamparo se afirma em uma nudez que está além dos corpos, "a modelar campinas no vazio/ da alma, que é apenas alma". Aqui, Carlos, seu corpo separa-se de uma história escrita por outros (amparada por outros) para ir ao encontro de uma história escrita por ele mesmo (amparada-desamparada por ele mesmo). A alma-apenas alma não é uma essência unitária boa ou má, mas sabe que o sentido de qualquer ação humana é dado posteriormente a ela, uma vez que, originalmente, ela é dupla, indecidível, além do bem e do mal.

Isso mostra como uma mesma ação é continuamente reproduzida segundo os mais variados valores e sentidos, sendo sempre enviada a ter um sentido que nunca esteve, de fato, presente. ${ }^{44}$ A imagem da construção de campinas no vazio permite que vejamos a poesia como um movimento discursivo, e não como um ser acabado, completo. O texto, como a alma, como o corpo, é sempre virgem e está sempre disponível a novas inscrições. ${ }^{45}$ Como o presente significado de um dado texto ou corpo é sempre reconstituído retardariamente, só nos resta entender esse movimento contínuo e ambivalente como força mobilizadora, como um desamparo que não é desesperador, mas criativo, narrativo, onde sempre é possível uma apropriação das "políticas do amparo" alheias. Em outras palavras, Carlos, você soube, como poucos, fazer de uma história que era ainda a dos outros uma outra história que era sua. Mais bonita ou não que a de Robinson Crusoé, $^{46}$ ela era sua, mas atravessada pelas histórias de muitos e muitos outros:

A verdade essencial

É o desconhecido que me habita

E a cada amanhecer me dá um soco.

42. ANDRADE, 1988. p. 102: "Nudez".

43. ANDRADE, 1988. p. 102: "Nudez".

44. DERRIDA, 1971. p. 200.

45. Estamos aqui aproveitando a metáfora da escrita do psiquismo como "bloco mágico" de Freud, aproveitada posteriormente por Derrida. Cf. DERRIDA, 1971. p. 214-229.

46. ANDRADE, 1988. p. 44-45: "Infância". 
Por ele sou também observado

Com ironia, desprezo, incompreensão.

$\mathrm{E}$ assim vivemos, se ao confronto se chama viver,

Unidos, impossibilitados de desligamento,

Acomodados, adversos,

Roídos de infernal curiosidade.

Ou então:

A minha festa,

O meu nascer poreja a cada instante

Em cada gesto meu que se reduz

A ser retrato,

Espelho,

Semelhança

De gesto alheio aberto em rosa.

Assim, Carlos, você faz do seu rosto, do seu corpo, da sua história, da sua poesia algo que não é apenas seu. Não há unidade, essência, permanência na sua poesia, uma vez que ela participa daquela estranha possibilidade que Bhabha chama de terceira escolha. Essa escolha nos dá um corpo que é menos do que um e duplo. Não estamos mais no "vel da alienação" de Lacan. ${ }^{49}$ A terceira escolha é um modo de apropriação que torna o discurso do outro acessível, para que o sujeito possa fazer uso dele de sua própria maneira e estabelecê-lo em uma

47. ANDRADE, 1988. p. 147: "O Outro".

48. ANDRADE, 1988. p. 142: "Nascer de Novo".

49. O conceito de alienaçâo em Lacan corresponde a um ou/ou (um vel, como no latim), a uma escolha exclusiva entre duas partes, a ser decidida, pela luta, até a morte de uma das partes. No entanto, é sempre a mesma parte que é excluída, tornando a escolha uma ilusão. O exemplo clássico de Lacan é a proposição dos assaltantes: "A bolsa ou a vida?", onde fica claro que a escolha, na verdade, não existe. A opção que interessa aqui não é entre a bolsa ou a vida, mas entre o sujeito e o Outro, atribuindo-se ao sujeito a posição do perdedor. Como conclui Fink: "No vel de Lacan, os lados não são de modo algum equilibrados: na confrontação com o Outro, o sujeito imediatamente sai de cena. Enquanto a alienação é o 'primeiro passo' imprescindível para ascender à subjetividade, esse passo envolve escolher 'o próprio' desaparecimento". FINK, 1998. p. 74. Grifos do autor. 
ordem de coisas que o libera de qualquer subordinação. ${ }^{50}$ Assim, entre amparar ou desamparar, você escolheu amparar desamparando e desamparar amparando. O que é extremamente delicado de sua parte. E profundamente devastador.

Segundo entendo, essa apropriação de toda uma política do amparo viciada e viciosa tem por objetivo fazer funcionar o amparo sob seu duplo opositivo, assim como faz movimentar e deslocar o desamparo sob a perspectiva do consolo. Esse trabalho de deslocamento quer resistir, permanentemente, ao jogo metafísico da oposicionalidade, que sedimenta nossa cultura sob a lógica da posição. Essa atividade profunda da sua poesia, sempre resistente, que Antonio Candido chamou de inquietude, ${ }^{51}$ incorpora o desejo por um universo humano mais móvel, onde posições obrigatórias possam ser motivo de riso, de escárnio ou de concórdia, mas que sejam motivo de, que movimentem as coisas, que desloquem, que resistam.

Assim, podemos ouvir:

\author{
Um não-estar-estando \\ Mas de tal jeito urdidos \\ O jogo e a confissão \\ Que nem distingo eu mesmo \\ $\mathrm{O}$ vivido e o inventado \\ Tudo vivido? Nada. \\ Nada vivido? Tudo. \\ A orelha pouco explica \\ De cuidados terrenos \\ $\mathrm{E}$ a poesia mais rica \\ É um sinal de menos.
}

Assim, os corpos ficam, não ficam, fogem, somem, voltam. Cada corpo, humano ou poético, parecerá estranhamente o mesmo e outro. As fronteiras se confundem nessa luminosidade parcial, duplicada por fantasmas móveis de outros corpos, de outros tempos. O que nos coloca definitivamente

50. Apropriei-me da explanação de Victor Smirnoff acerca da separação do fetiche. Cf. SMIRNOFF, V. N. The fetishistic transaction. In: LEVOBICI, S., WIDLOCHER, D. (Ed.). Psychoanlaysis in France. New York: International University Press, 1980. p. 307. Apud: BHABHA, 1998. p. 174 .

51. CANDIDO, 1970

52. ANDRADE, 1988. p. 41-42: "Poema-Orelha". 
distantes do mundo. E, ao mesmo tempo, estranhamente próximos. Amparadosdesamparados, continuados por uma lógica estranha e híbrida onde o seu trabalho continua, Carlos; continuamos a ler sua poesia e fazer dela nossa pele. Cada discurso seu, mal traduzido, é transformado e repetido em diferença. Assim, passa a fazer efeito de forma estranha. Funciona de forma enevoada e nebulosa. Criam sentidos novos. Criam novas histórias. Novas e velhas muletas. Antigos e renovados esquecimentos.

Não, Carlos, nem coração nem corpo são maiores ou menores ${ }^{53}$ que nada. Nem o mundo mesmo, o corpo estupidificado do mundo é maior ou menor que nada. Continuemos, Carlos, apenas continuemos. As muletas estão aí.

Abstract: This is a study of the support issue in Carlos Drummond de Andrade. The ordinary policy of support to the buman fallibility and the reduction of human complexity are argued by the poet. Through a poetic strategy - which is underpinned by ambiguity, restlessness and values displacement - Drummond changes the aims of the literature activity, leading it to a more political and less compensative realm.

Key words: ambiguity, values, politic.

53. ANDRADE, 2001. p. 173: "Mundo Grande". 
ANDRADE, Carlos Drummond de. Literatura Comentada. Seleção de textos, notas, estudos biográfico, histórico e crítico por Rita de Cássia Barbosa. São Paulo: Nova Cultural, 1988.

Farewell. Rio de Janeiro: Record, 1996.

Sentimento do mundo. Rio de Janeiro: Record, 2001.

ASSIS, Machado de. Esaú e Jacó. São Paulo: Globo, 1997.

BHABHA, Homi K. O local da cultura. Trad. Myriam Ávila, Eliana Lima Reis, Gláucia Gonçalves. Belo Horizonte: Editora UFMG, 1998.

CANDIDO, Antonio. Inquietude na poesia de Drummond. In: Vários escritos. São Paulo: Duas Cidades, 1970.

CUNHA, Euclides da. Os Sertões: campanha de Canudos. Rio de Janeiro: Francisco Alves, 1981.

DERRIDA, Jacques. A escritura e a diferença. Trad. Maria Beatriz M. Nizza da Silva. Rev. Mary A. L. de Barros. São Paulo: Perspectiva, 1971.

FINK, Bruce. O sujeito lacaniano: entre a linguagem e o gozo. Trad. Maria de Lourdes Sette Câmara. Rio de Janeiro: Jorge Zahar, 1998.

MELO NETO, João Cabral. Obra completa. Marly de Oliveira (Org.). Rio de Janeiro: Nova Aguilar, 1994.

SANTIAGO, Silviano (Org.). Glossário de Derrida. Rio de Janeiro: Francisco Alves, 1976. 